\title{
SALINITY VARIATION IN INTERSTITIAL WATER OF SAND AT KAMES BAY, MILLPORT, WITH REFERENCE TO THE DISTRIBUTION OF NEREIS DIVERSICOLOR
}

\author{
By Ralph I. Smith \\ Department of Zoology, University of California, Berkeley, California \\ (Text-figs. I-5)
}

The sheltered beach of Kames Bay, Millport, Isle of Cumbrae, Scotland has been the scene of several important studies on intertidal zonation (Stephen, I929; Elmhirst, I93I; Watkin, I942). The last paper is most comprehensive and records in detail the zonation of over twenty species of animals. In the course of the present study I have found Watkin's account very accurate, but incomplete in respect to salinity variation in the interstitial water of the sands. My attention was initially directed to Kames Bay in a search for a population of Nereis diversicolor O. F. Müller inhabitating an essentially 'marine' environment in respect to salinity. The suitability of Kames Bay was suggested by a statement of Watkin (1942, p. 558):

The salinity of the tidal water may be expected to agree with that of the waters of the Firth and to show little or no variation from high to low water, and to be about 32 parts per thousand.... The extent of the fresh-water influence in Kames Bay is very slight. A small stream crosses the beach on its western edge, but the line of sampling is some distance from it.

And on p. 544:

the volume of water of this stream is small and the effect over the whole bay cannot be considered as seriously affecting the type of fauna.

The present report will give evidence that other sources of fresh water in Kames Bay, apart from the small stream mentioned above, are not insignificant, and that the distribution of $N$. diversicolor on the beach may be correlated with the occurrence of brackish water.

As shown in Fig. I, the western third of the beach is subject to the run-off of a smaller and a larger freshwater stream issuing from culverts in the sea wall. In October 1953, samples of interstitial water were taken along a transect (A) running seaward across the slope affected by these freshwater rivulets. $N$. diversicolor was found to occur in rather uniform numbers along this line, from a point $35 \mathrm{~m}$ from the sea wall (i.e. below the high-water neaptide level) out to $90-100 \mathrm{~m}$. The chloride of the interstitial water varied from 
5 parts per mille at $35 \mathrm{~m}$ to $\mathrm{I} 6 \%$ at $\mathrm{I00} \mathrm{m}$ (that is, salinities of 9 and $29 \%$ respectively). These values were maintained beneath nearly fresh overflowing stream water during low tide (at $100 \mathrm{~m}$ the flowing surface stream had a chloride of $2.4 \%$ ). Such a situation has been repeatedly observed in estuarine environments (Reid, I930, I932; Alexander, Southgate \& Bassindale, 1932). The broad distribution of $N$. diversicolor contrasted, however, with the narrow zonal grouping reported by Watkin, and seemed possibly related to the wide zone of freshwater influence. As a check of this supposition a second transect (B) was established near the centre of that two-thirds of the beach presumed to be free of freshwater influence. The results of preliminary sampling on transect $\mathrm{B}$ showed the expected sharper zonal grouping of $N$. diversicolor, but also an unexpected band of low interstitial salinity extending along the beach in the zone of greatest abundance of the worm. This finding prompted a more careful examination of this part of the beach and of the salinity profile of the interstitial water.

\section{General Description of THe BeACH}

In October 1953, the beach presented a distinct 'upper slope' of loose sand with windrows of debris and cast wrack, commencing close to the sea wall, approximately at the high-water mark of the highest spring tides (EHWS), and ending some $35 \mathrm{~m}$ to seaward, $2 \mathrm{ft}$. or so vertically below the high-water mark of neap tides. From the foot of the upper slope there extended seaward a 'middle flat' of smooth, usually ripple-marked, sand which at about 80-90 m from eHWs began to slope more noticeably to seaward. Roughly, the start of this 'outer slope' coincided with the seaward margin of the zone of Arenicola marina and the beginning of the zone of Nephthys sp. Along the inner margin of the middle flat part of the beach, a series of shallow pools retained a layer of water even at low tide. These depressions probably resulted from the churning effect of mild surf action at high water, and the steeper upper slope to wave wash at such times. The outer slope may be the result of comparable periods of wave action at low tide. Without going into detail, it is clear from the generally sinusoidal form of the tidal curve at Millport that the upper and lower slopes must experience relatively longer periods of breaking waves than does any similar area of the middle flat, over which the tide advances and retreats more rapidly, and of course the sigmoid configuration of the beach profile, once established, further accentuates the differences in duration of wave action resulting from the character of the tidal curve. It is in the relatively stable middle flat that Nereis and Arenicola are established in large numbers. The presence of these forms has been stated by Dahl (1952) to be characteristic of mud flats rather than of sand beaches of the sort whose zonation he has recently described, and it might not be unfair to characterize this part of the Kames Bay sands as a mud flat lacking mud. In stormy weather and throughout the winter months the long wash and sweep of waves. 
tend to fill in the angle at the foot of the upper slope. By November 1953, the foot of the upper slope had advanced about $10 \mathrm{~m}$ seaward from its earlier level, and by February 1954, the beach presented an uninterrupted, slightly concave, slope from the centre of the middle flat nearly to EHws mark. The morphology of the beach is obviously not static, but represents a dynamic equilibrium of complex forces.

The substratum varies somewhat in different parts of the beach, the upper slope being of noticeably coarser sand than the middle or outer zones. However, the populated parts of the beach are, on the whole, of remarkably uniform particle size (according to Watkin, chiefly $0.2-0.5 \mathrm{~m}$ ) with a very small fraction of silt or clay, and no black deposits in the areas studied. The most striking discrepancy in substrate occurs at the foot of the upper slope where the sand is cut away in summer to a thin layer about 3 in. deep, overlying some 3 in. of stony gravel, and this in turn covering a hard layer of mixed stones embedded in fine reddish sand.

A most noticeable feature of that section of the beach which receives no surface streams of fresh water is the fact that the lower half of the upper slope and the middle flat to seaward of its foot remain continuously wet and glistening at low tide. The appearance suggests that subsurface seepage reaches the surface of the sands above the line where the upper slope terminates, and that it permeates the sands of the middle flat for a considerable distance. This band of wetness occupies the greater part of the width of the beach. A small well-drained band occurs near the ledges bounding the beach on the east, and a wider 'dry' band is found in approximately the centre $15-20 \%$ of the beach just to the east of the main stream. The characteristic wetness of the sands in the rest of the beach seems to be present regardless of immediate weather conditions. It has been observed in the course of this study from October to April, and is evident in an aerial photograph taken in August 1947 (Fig. 2). Since this drainage appears to be of fresh water, the sands of the inner edge of the middle flat must be to some extent exposed to brackish conditions during the period of low tide. It might be assumed that any intrusion of brackish water would be replaced by sea water at high tide, but this is not necessarily so, and it appears from the literature that few workers have considered in detail the possible variations of salinity in the interstitial water that may occur on sand beaches during the tidal cycle. Bruce (1928) discusses surface and subterranean intrusion of fresh water on the beach at Port Erin and concludes from a single series of observations that '.. there is a progressive fall in salinity [of the interstitial water] from the time the beach is uncovered until the advancing tide has nearly reached the point of observation, when the salinity rapidly rises to the full sea-value'. No interstitial salinities were recorded from beneath sea water, and it seems probable that Bruce was working in an area of surface drainage of fresh water. Pirrie, Bruce \& Moore (1932) did not attach much importance to lowered interstitial 
salinity at Port Erin, for they conclude that 'no very close correlation must be looked for between the distribution of the fauna and the salinity of the beach'. Emery \& Foster (1948) have shown that the salt-water table in the sands of exposed Californian beaches rises and falls with the tides, but lagging

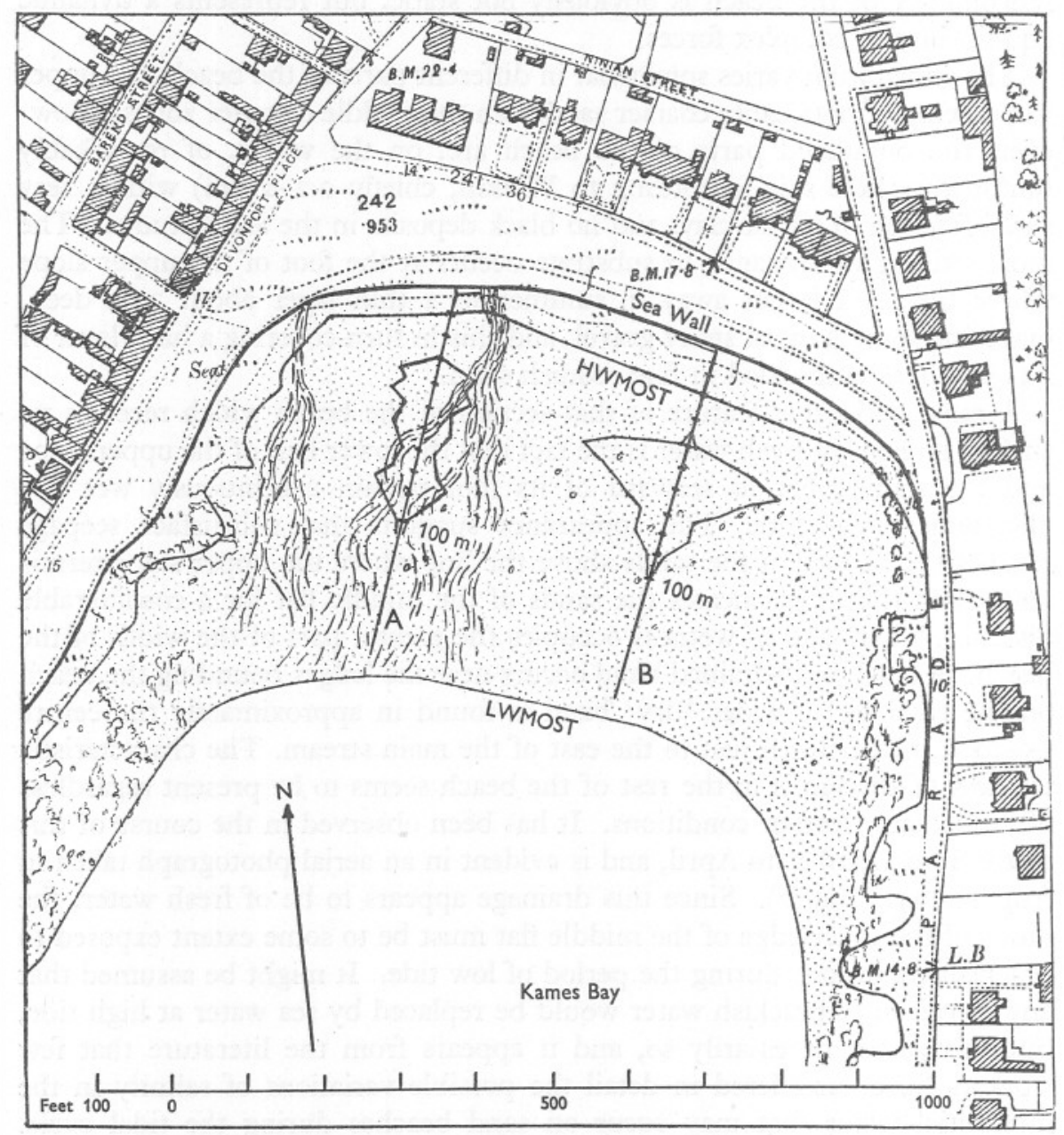

Fig. I. Map of Kames Bay, a composite from Ordnance Survey sheets, Buteshire, CCXVI-Io \& II and - I4, I896 edition, I:2500; reproduced by permission of Ordnance Survey Office. Sea wall, streams, and transects A and B added. Polygons on transects show relative density of $N$. diversicolor.

by $\mathrm{I}-3 \mathrm{~h}$ and with decreasing amplitude as the land is approached. Such a fluctuating salt-water table might be of considerable importance to animals of the upper mid-tidal sands. In attempting to assess the importance of the apparent freshwater intrusion into the Nereis zone at Kames Bay, two possi- 
bilities were considered: (I) If the interstitial drainage from the land were super-imposed upon a fluctuating salt-water base, the freshwater layer might

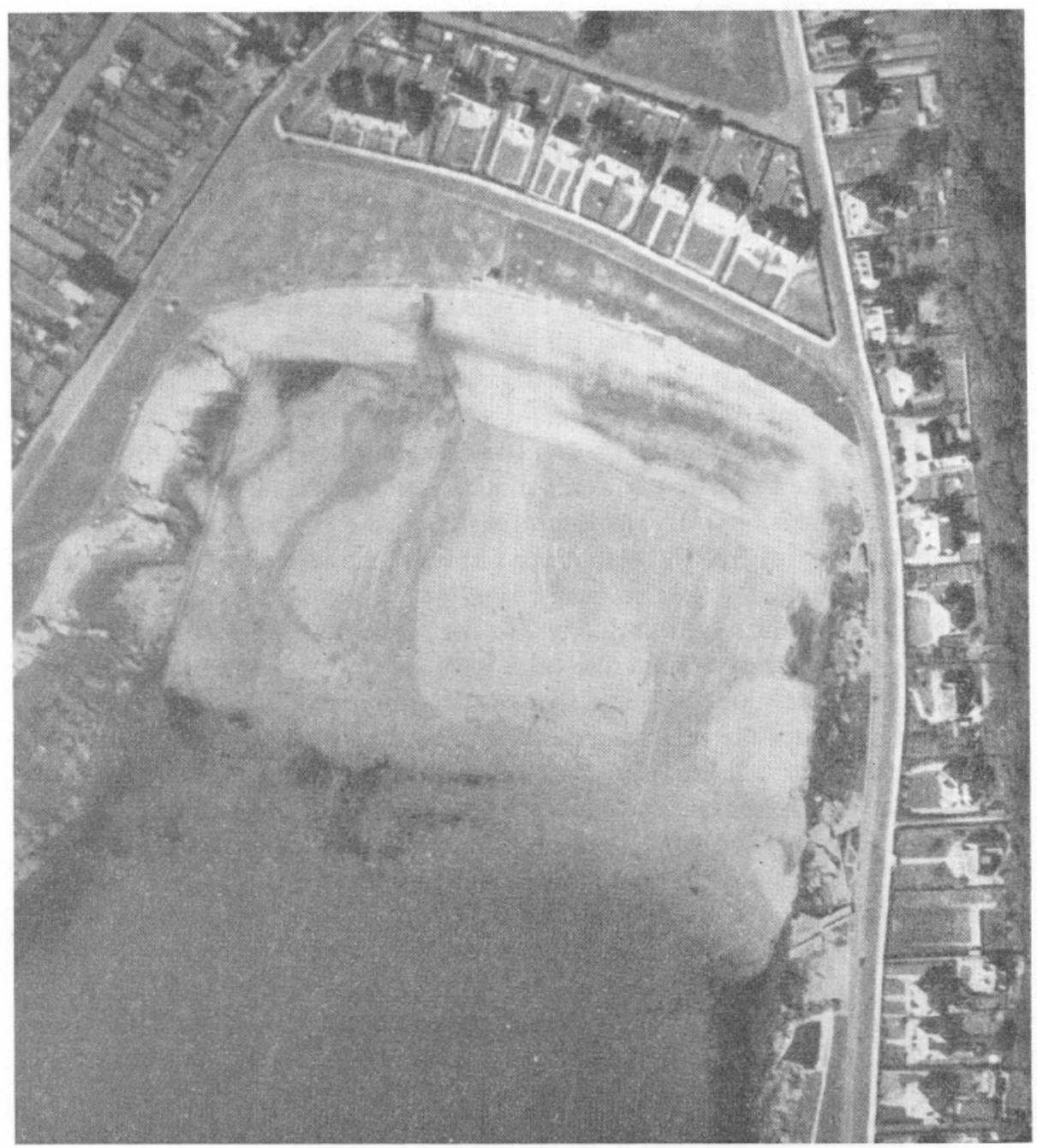

Fig. 2. Unretouched aerial photograph of Kames Bay, apparently at low tide, August I947, showing as a darker area the position of the wet band in the upper slope of beach. (R.A.F. photo no. 4103, CPE/SCOT/UK/26I, I3 August 47, F/20'/r6,600', 82 Sqdn. Crown Copyright Reserved. Published by permission of the Air Ministry.)

be elevated at high tide so that the nereid zone would receive fully saline sea water twice daily. But if (2) the level of freshwater drainage were determined by geological factors which precluded oscillation of the salt-water table, then 
it would be possible to conceive of a situation where fresh water flowed at a fixed level regardless of the tide, and so penetrated the nereid zone beneath the incoming tide, subject to mixing with the overlying sea water. The latter possibility would be of obvious interest when one considers the occurrence of such a typically estuarine form as $N$. diversicolor on an apparently marine beach.

\section{Methods}

Transects A and B are indicated in Fig. I and may be readily located by reference to houses near the bay. Transect $\mathrm{B}$, on which most work was done, started at the lower eastern corner of the sloping concrete apron at approximately EHWS mark and ran directly seaward. Distances were measured with a $25 \mathrm{~m}$ length of trawl line marked off in I and $5 \mathrm{~m}$ intervals. Although subject to error by stretching, it gave sufficiently reproducible results for the purpose. Water samples were sucked up from a depth of 6 in. beneath the sand surface by means of a rubber tube and a stiff plunger, originally of Pyrex tubing (of $5 \mathrm{~mm}$ bore, flamed down at tip to $\mathrm{I} \mathrm{mm}$ ), later replaced by a brass tube of comparable dimensions. It was found best to make the orifice large enough to admit sand grains freely; these tended to settle and did not seriously interfere with sampling. For use in coarse sand the orifice is better placed at the side of the tip rather than terminally. In use, the plunger was pushed to the desired depth (a large cork on the tube formed a stop), a sample sucked up and discarded, the tube re-inserted while blowing to exclude water, a second sample brought up, the tube wiped off, a small quantity of water discharged, and the remainder collected in a vial. When subsurface samples are taken in this simple way from beneath overlying sea water there is likelihood of contamination, but as such would only tend to lessen the differences observed, the general conclusions reached would not be invalidated. Aliquots of $\mathrm{I} \mathrm{ml}$. were titrated from a $5 \mathrm{ml}$. burette with $\mathrm{AgNO}_{3}, 19 \cdot 16 \mathrm{~g} / 1$., equivalent to $4 \mathrm{~g}$ chloride per litre, standardized against a carefully prepared solution of $\mathrm{NaCl}$ (equivalent to Io $\mathrm{g}$ chloride per litre), diluting each aliquot with $\mathrm{Io} \mathrm{ml}$. of distilled water and using $5 \%$ potassium chromate indicator. Since this procedure is not that of standard hydrographic practice, the results have been expressed in grams of chloride per litre at room temperature (a value approximating 'chlorosity') rather than as 'chlorinity'. The differences, for our purpose, are inconsequential. For obtaining the density of worms at each station a square box of galvanized sheet-iron without bottom, of $\frac{1}{10} \mathrm{~m}^{2}$ area, was pressed into the sand to a depth of 6 in., the enclosed sand dug out, and washed through a sieve of 16 meshes to the inch. Only $N$. diversicolor were collected; counts are expressed in numbers of heads obtained regardless of size, although it was noted that the larger worms were more abundant at about the 50-60 m level. Transect B was studied on 3I October-2 November I953, I2-I3 February, and I8 March 1954, with special attention paid to obtaining 
interstitial water samples from beneath overlying sea water at high tide or during the ebb, when salinities in the sand might be expected to be maximal. Unpublished rainfall and salinity data recorded at the Millport Laboratory were kindly made available by Dr H. Barnes.

\section{OBSERVATIONS (TRANSECT B)}

3I October-2 November I953. Two series of water samples were taken on falling tides and one on a rising tide; one series of collections of $N$. diversicolor was taken at corresponding stations. On I November the transect was sampled successively 5 times, from $\mathrm{I}$ h past the start of the ebb until the turn of the tide. On this day the foot of the upper slope lay at $50 \mathrm{~m}$ from EHws mark, having advanced somewhat from the mid-October position, but the break at its foot, where the stony layer lay close beneath the surface, was still distinct. It was raining intermittently, following a fortnight of heavy rains (the Marine Station had recorded 5.39 in. of rain in the previous 15 days). The interstitial chloride profiles (Fig. $3 \mathrm{~A}-\mathrm{F}$ ) indicated a brackish zone which tended to move seaward as the tide fell, and which was distinct even beneath the shallow wash of the retreating sea water. As the tide fell, the surface water became progressively less saline, probably as the combined result of dilution by subsurface drainage and of lateral mixing with fresh water from the streams to the west. Under the conditions of high freshwater discharge prevailing that day the chloride of the bay water was lowered from I 7 to $12 \cdot 8 \mathrm{~g} / 1$., but at the turn of the tide the inflooding sea water had a nearly normal chloride value of $17 \mathrm{~g} / 1$. (= salinity of $30.5 \%$ ).

On 2 November, two series of interstitial water samples taken beneath sea water up to $20 \mathrm{in}$. deep on the falling tide confirmed the results of the previous day and showed more clearly the low salinity of the interstitial water beneath ebbing sea water (Fig. $3 \mathrm{G}, \mathrm{H}$ ). The lowering of subterranean chloride was apparent out to 50-60 m from EHws mark. The possibility was considered that these results reflected abnormal conditions caused by heavy rainfall in the previous 2 weeks.

I2-I3 February I954. The earlier work was repeated following a period of relatively dry weather. There had been rains on 5-6 and 9-Iò February, but the total rainfall for the previous $\mathrm{I} 7$ days had been only $\mathrm{I} \cdot 57$ in. By this time winter storms had so smoothed out the upper half of the beach that no break was apparent between upper slope and middle flat. Several inches of sand had been deposited above old burrows of $N$. diversicolor, but with little or no displacement of the population. The zone of Arenicola was unaltered. One salinity profile was taken during rain on 12 February on a rising tide and a second series of three in light rain on the ebbing tide, I3 February. The chlorides obtained on the falling tide (Fig. 4) agreed with the previous findings, brackish interstitial water being evident beneath sea water and detectable out to $60-70 \mathrm{~m}$, about to the inner edge of the zone of Arenicola. 


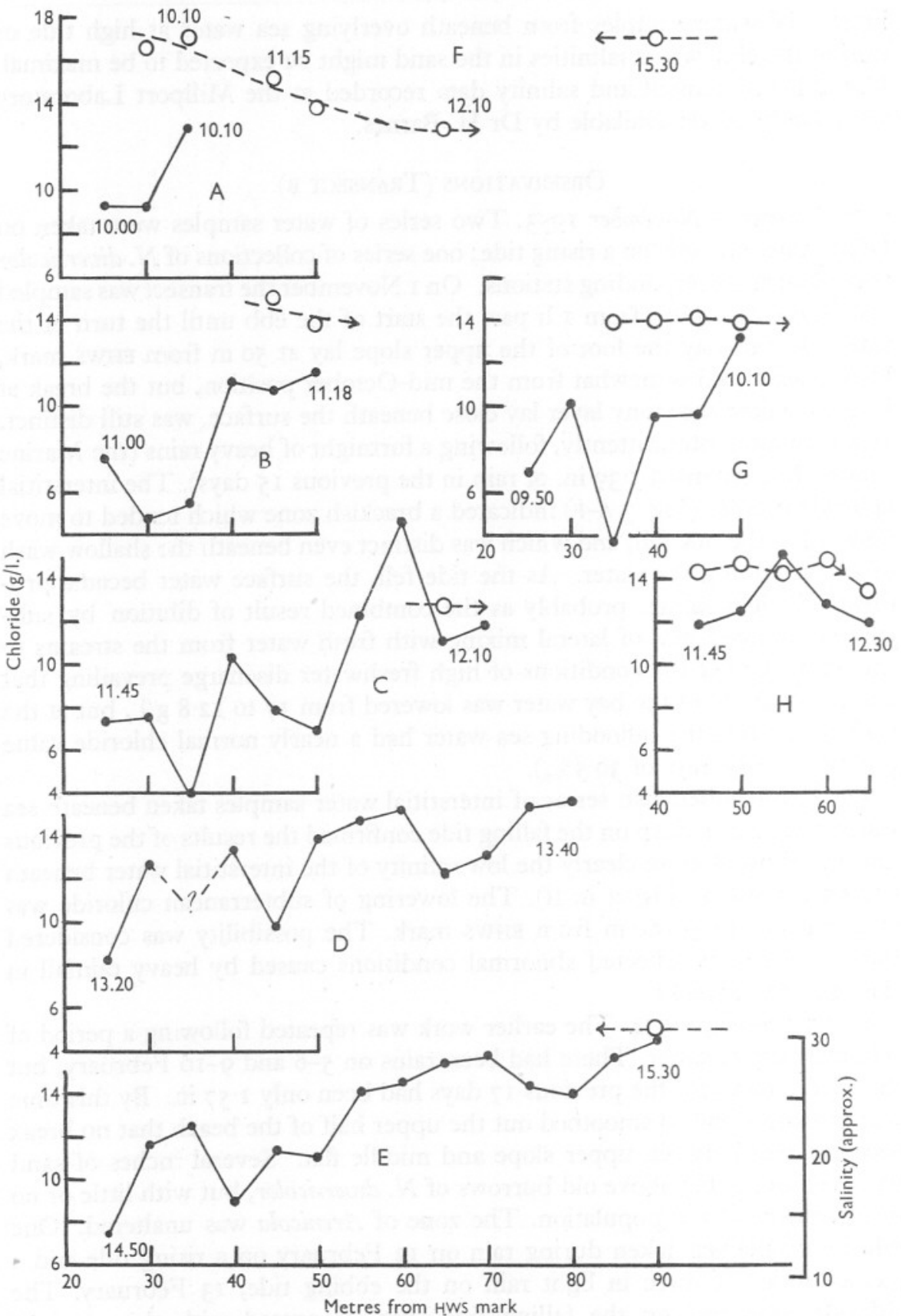

Fig. 3. I-2 November 1953 . Solid curves A-E, chloride of interstitial water on falling tide I November, taken successively at times indicated; dashed curves, chloride of overlying sea water, plotted collectively as curve $\mathrm{F}$, the point at 15.30 being at start of rising tide. Insets $\mathrm{G}$ and $\mathrm{H}$, similar, for falling tide on 2 November. 
SALINITY OF KAME BAY SAND

$4 \mathrm{I}$

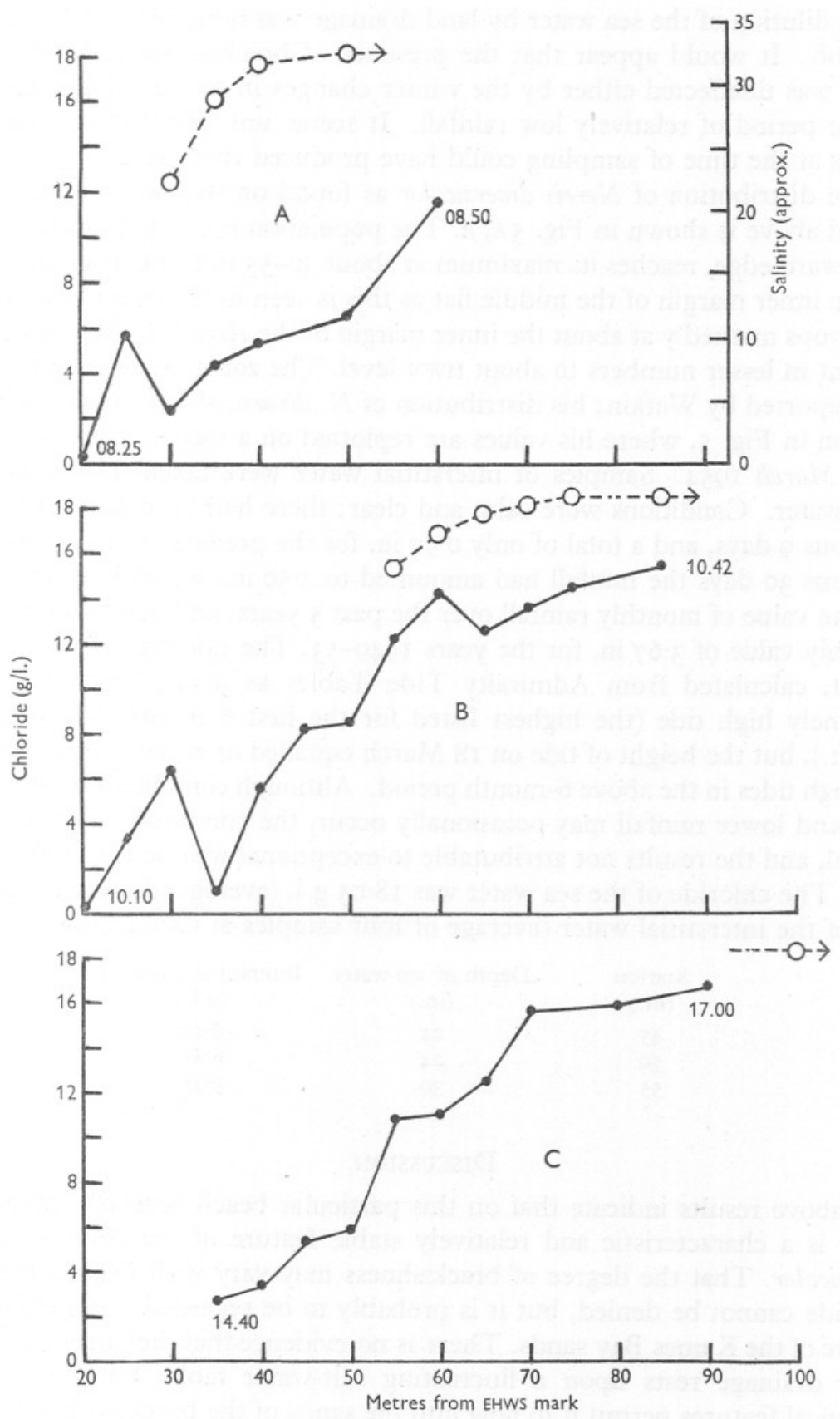

Fig. 4. I3 February 1954, falling tide. Solid curves, interstitial chloride; dashed curves, chloride of overlying sea water. Times of sampling as indicated. 
Some dilution of the sea water by land drainage was noticeable at the start of the ebb. It would appear that the presence of brackish water beneath sea water was unaffected either by the winter changes in beach configuration or by the period of relatively low rainfall. It seems unlikely that rain actually falling at the time of sampling could have produced these results.

The distribution of Nereis diversicolor as found on the two occasions discussed above is shown in Fig. 5A, B. The population is sharply limited on its shoreward edge, reaches its maximum at about $50-55 \mathrm{~m}$ from EHWs mark (i.e. on the inner margin of the middle flat as this is seen in the summer months), and drops markedly at about the inner margin of the Arenicola zone, although present in lesser numbers to about HWN level. The zonation agrees well with that reported by Watkin; his distribution of $N$. diversicolor is shown for comparison in Fig. 5, where his values are replotted on a metric scale.

I8 March 1954. Samples of interstitial water were taken from a boat at high water. Conditions were calm and clear; there had been no rain for the previous 9 days, and a total of only $0.97 \mathrm{in}$. for the previous I6 days. For the previous 30 days the rainfall had amounted to $3.50 \mathrm{in}$., which is close to the median value of monthly rainfall over the past 5 years, and below the average monthly value of 3.67 in. for the years 1949-53. The tide was above average height, calculated from Admiralty Tide Tables as $9.7 \mathrm{ft}$. This is not an extremely high tide (the highest listed for the first 6 months of 1954 was II $.5 \mathrm{ft}$.), but the height of tide on I8 March equalled or exceeded $7 \mathrm{I} \%$ of the 303 high tides in the above 6-month period. Although combinations of higher tides and lower rainfall may occasionally occur, the conditions seemed quite typical, and the results not attributable to exceptional weather or tidal conditions. The chloride of the sea water was $18.05 \mathrm{~g} / \mathrm{l}$. (average of three samples); that of the interstitial water (average of four samples at each station):

$\begin{array}{ccc}\begin{array}{c}\text { Station } \\ (\mathrm{m} .)\end{array} & \begin{array}{c}\text { Depth of sea water } \\ \text { (in.) }\end{array} & \begin{array}{c}\text { Interstitial chloride } \\ (\mathrm{g} / 1 .)\end{array} \\ 45 & 22 & 9 \cdot 14 \\ 50 & 24 & 6 \cdot 85 \\ 55 & 30 & .\end{array}$

\section{Discussion}

The above results indicate that on this particular beach brackish interstitial water is a characteristic and relatively stable feature of the zone of Nereis diversicolor. That the degree of brackishness may vary with season, rainfall, and tide cannot be denied, but it is probably to be regarded as a permanent feature of the Kames Bay sands. There is no evidence that the intrusive freshwater drainage rests upon a fluctuating salt-water table, but rather that geological features permit it to flow into the sands of the beach with sufficient head to maintain brackish conditions in the sand even at high tide. Such conditions may be peculiar to this beach and are not necessarily to be found 

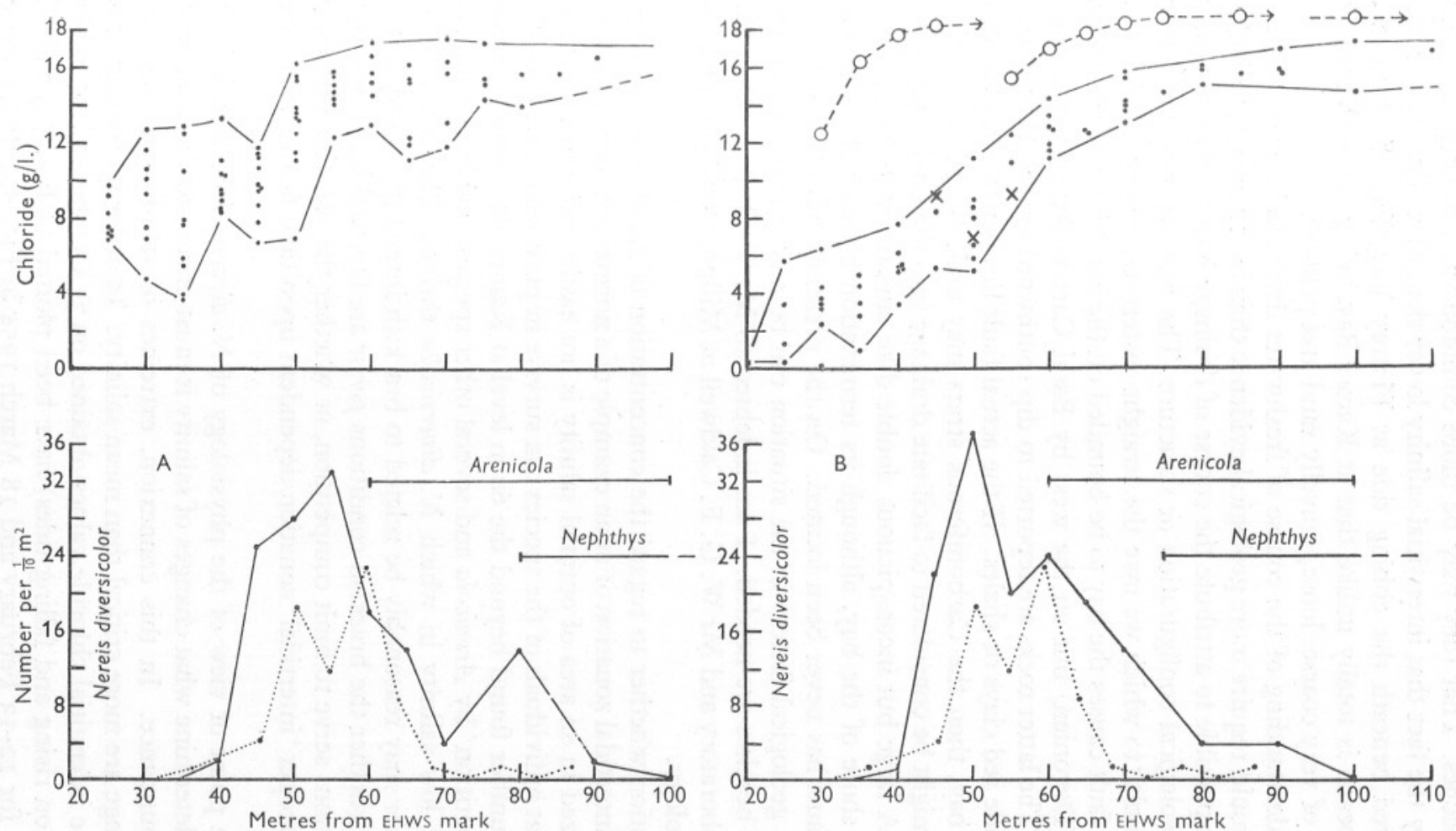

Fig. 5. A (upper), distribution of interstitial chlorides on one rising and two falling tides, 3I October-2 November 1953; B (upper), same for one rising and one falling tide, I2-I3 February 1954, plus chlorides of overlying seawater during ebb I3 February and interstitial chloride $(X)$ at high tide I8 March. A, B (lower), distribution of $N$. diversicolor in present studies (solid curves) in worms per O.I $\mathrm{m}^{2}$. Dotted curves show distribution of N. diversicolor as reported by Watkin (I942), replotted on metric scale. Horizontal bars indicate range only of certain other polychaetes as noted in present study. 
on other beaches. That they may be more common than hitherto noted is suggested by the fact that interstitial salinity lower than that of sea water has been observed beneath the ebbing tide at Fintray Bay, Isle of Cumbrae, where the beach is totally unlike that at Kames Bay, being exposed, steeply sloped, and of very coarse, loose, gravelly sand and pebbles.

A full understanding of the course of freshwater drainage into the Kames Bay sands would require more geological evidence than is at present available, and it is not possible to attribute the course of drainage into the beach to any particular geological configuration or structure. The bay includes the Great Cumbrae Fault 'to which we owe the straight eastern boundary...' (Gunn, 1903). This fault causes the bay to be bounded on the east by Upper Old Red Sandstone (Devonian) but on the west by Basal Carboniferous Calciferous Sandstone. The latter rocks are reported to dip southward toward Kames Bay and to include red clays or shales. If the actual fault lies beneath the eastern side of the bay, then the Carboniferous strata may underly the site of this study, and might be considered to facilitate drainage into the sands, but proof is lacking. A large but inconspicuous double dike cuts through the rocks at the eastern shore of the bay, although its termination beneath the sands at the actual fault has never been located. On the present evidence no assessment of the geological factors in the situation can be made; more studies on a variety of beaches are needed. I am indebted to $\mathrm{Mr} \mathrm{T}$. B. Bagenal of the Millport Laboratory and Mr W. G. E. Caldwell of Millport for discussions of the local geology.

The question whether to regard the concentration of $N$. diversicolor as an instance of intertidal zonation or as an example of a normally estuarine species being localized in an area of optimal salinity is not easily answered. There is no doubt that individuals of the species can survive in pure sea water. Possibly the lesser number found beyond the $60 \mathrm{~m}$ level at Kames Bay simply results from 'competition' by Arenicola and several other species unable to populate the zone of low salinity in which $N$. diversicolor thrives. The zonation of $N$. diversicolor may reasonably be related to brackish interstitial water, but it is not clear whether the brackish conditions per se are favourable, or whether these conditions serve to limit competition, or whether the zonation observed is in part a proper 'intertidal' zonation dependent upon tidal factors exclusive of salinity.

From the point of view of the physiology of $N$. diversicolor itself, it is of interest to determine what changes of salinity it must encounter in its zone of maximal abundance. In this connexion, extremes of salinity and rates of salinity change are more critical than mean salinity. In order to examine this point, all the interstitial chloride values obtained on 3I October-2 November I953 (both on rising and falling tides) have been plotted in Fig. 5A, and all such values for I2-I3 February and I8 March 1954 in Fig. 5B. From these charts, in which the extremes of chlorinity are outlined, it would appear that 
whereas Arenicola marina must seldom encounter chlorinities below I2 parts per mille in Kames Bay, the bulk of the nereid population may regularly in the course of a day have to endure chlorinities between I2 and 5-6\%, and some must experience chlorinities as low as $4 \%$. That this is well within the tolerance of the population is suggested by laboratory experiments in which worms from Kames Bay have been adapted by steps to chlorinities as low as $0.25 \%$. This is about $\mathrm{I} \cdot 4 \%$ of Millport sea water, which has a mean chlorinity of $17.76 \%$ (= salinity $32.90 \%$ ), with monthly chlorinity means varying from I8. 43 to I6.55\% (based upon 5-year period June I948 to May I953).

If the field observations reported here may be regarded as of typical conditions, Nereis diversicolor is not exposed at Kames Bay to salinities which in themselves approach the limit of its osmotic tolerance. It is likely that at high tide the worms experience salinities above the values observed for the interstitial water, since these worms probably resume irrigation (and may emerge to feed) as soon as the rising sea water covers them (Wells \& Dales, I95I). Hence, while the actual salinity endured at low tide may be that of the interstitial water, the salinities experienced at high tide must be the resultant of circulated sea water being diluted by brackish water in the sand about the burrows. The fact that brackish water remains available may well protect the worms against too abrupt rises of salinity at each high tide, and thus lessen the impact of salinity changes, somewhat as does the salt-water content of estuarine flats exposed to over-flowing fresh water at low tide. The actual rate of change of salinity experienced by $N$. diversicolor at Kames Bay cannot be determined from the present data, but an inspection of Fig. 5 suggests that in the zone of maximal abundance the worms experience a change in chlorinity of not less than 6 parts per mille per tidal rise or fall, and probably within $2 \mathrm{~h}$.

These studies were carried out while the author held a Fulbright Exchange Lectureship in the Zoology Department, University of Glasgow. Field work and analyses were done at the Scottish Marine Biological Association Laboratory at Millport, to whose Director and staff I am grateful for much kindness and assistance.

\section{SUMMARY}

An hitherto undescribed, relatively stable, zone of brackish interstitial water is reported from the upper mid-tidal sands of Kames Bay, Millport.

Lowered interstitial salinity persists even beneath overlying sea water at high tide. Present evidence does not permit evaluation of the geological factors involved.

The zonation of Nereis diversicolor on this beach seems correlated with the belt of lowered salinity, but it remains unclear whether the brackish conditions per se are favourable, or if they serve to limit competition from other species.

It would appear that the observed zonation is not purely dependent upon tidal factors exclusive of salinity. 


\section{REFERENCES}

Alexander, W. B., Southgate, B. A. \& Bassindale, R., I932. The salinity of the water retained in the muddy foreshore of an estuary. F. Mar. biol. Ass. U.K., Vol. I8, pp. 297-8.

BRUCE, J. R., I928. Physical factors on the sandy beach. Part I. Tidal, climatic, and edaphic. F. Mar. biol. Ass. U.K., Vol. 15, 535-52.

DAHL, E., I952. Some aspects of the ecology and zonation of the fauna on sandy beaches. Oikos, Vol. 4, pp. I-27.

Elmhirst, R., I93I. Studies in the Scottish marine fauna.-The Crustacea of the sandy and muddy areas of the tidal zone. Proc. roy. Soc. Edinb., Vol. 5I, pp. I69-75.

EMery, K. O. \& Foster, J. F., I948. Water tables in marine beaches. F. Mar. Res. Vol. 7 , pp. 644-54.

GunN, W., I903. The geology of North Arran, South Bute and the Cumbraes. Mem. geol. Surv. U.K. H.M. Stationery Office.

Pirrie, M. E., Bruce, J. R. \& Moore, H. B., I932. A quantitative study of the fauna of the sandy beach at Port Erin. F. Mar. biol. Ass. U.K., Vol. I8, pp. 279-96.

REID, D. M., I930. Salinity interchange between sea-water in sand and overflowing fresh-water at low tide. F. Mar. biol. Ass. U.K., Vol. I6, pp. 609-I4.

REID, D. M., I932. Salinity interchange between salt water in sand and overflowing fresh water at low tide. II. F. Mar. biol. Ass. U.K., Vol. I8, pp. 299-306.

STEPHEN, A. C., I929. Studies on the Scottish marine fauna: The fauna of the sandy and muddy areas of the tidal zone. Trans. roy. Soc. Edinb., Vol. 56, pp. 29I-306.

Watkin, E. E., I942. The macrofauna of the intertidal sand of Kames Bay, Millport, Buteshire. Trans. roy. Soc. Edinb., Vol. 60, pp. 543-61.

Wells, G. P. \& DALES, R. P., I95I. Spontaneous activity patterns in animal behaviour: the irrigation of the burrow in the polychaetes Chaetopterus variopedatus Renier and Nereis diversicolor O. F. Müller. F. Mar. biol. Ass. U.K., Vol. 29, pp. 66I-80. 